\title{
A centralidade da ressurreição para a fé cristã: A perspectiva Bultmaniana
}

\author{
Alessandro Rodrigues Rochal
}

\section{Introdução}

O lugar da ressurreição não é a história, mais a fé pascal dos primeiros Discípulos. Ou ainda, "O último dado ao alcance da ciência histórica é a fé pascal dos primeiros Discípulos" ". Nessa percepção sintética encontra-se o coração mesmo das proposições bultmanianas acerca da ressurreição.

Esse acento sobre a experiência de fé dos primeiros Discípulos está em continuidade com o deslocamento de eixo de toda a teologia neotestamentária de Bultmann. Esse deslocamento move do centro da teologia a figura de Jesus de Nazaré, colocando ali a querigma. Em suma, o histórico factual é substituído pela palavra como lugar da fé cristã.

Como interpreta Rosino Gibellini:

Mas como se realiza o evento da salvação? Onde encontrar Cristo? Na palavra anunciada e ouvida na fé: no querigma cristão ${ }^{3}$.

A palavra é o lugar da existência autêntica, onde a fé é entendida como liberdade perante o mundo, abandono radical a Deus, nova compreensão de si mesmo que abra caminho e confere clareza. É na palavra que se dá a renovação da existência ${ }^{4}$. O querigma, por sua vez, tem como núcleo a fé pascal.

\footnotetext{
${ }^{1}$ Doutorando em teologia sistemática pela PUC-Rio, coordenador acadêmico da FATERJ.

${ }^{2}$ BORNKAMM, Günther. Jesus de Nazaré. p. 295.

${ }^{3}$ GIBELLINI, Rosino. Teologia do Século XX. p. 40.

${ }^{4}$ Cf. GIBELLINI, Rosino. Op. Cit. P. 38 .
} 
A palavra da fé é a palavra pascal que lança luz sobre toda a realidade evangélica.

No intuito de compreender o que significa em Bultmann essa centralidade da ressurreição no querigma cristão, procederemos num itinerário que nos levará da constituição metodológica da teologia bultmaniana (relação com a teologia liberal e o existencialismo heidgeriano), ao seu projeto de demitização. Para então podermos perceber como ele entende a ressurreição e, como esta opera na fé cristã.

\section{A teologia existencial de Bultmann}

\subsection{Bultmann e a teologia liberal}

Até 1924, Bultmann ${ }^{5}$ se define como teólogo liberal ${ }^{6}$.Contudo, a partir da segunda metade da década de 20, quando publicou o ensaio $A$ teologia liberal e o mais recente movimento religioso, passa a considerá-la uma reflexão que diviniza o homem e desvia-se do seu objetivo teológico ${ }^{7}$. Essa crítica de Bultmann à teologia liberal, marca sua entrada na teologia dialética.

Nesta corrente teológica enfatiza-se a transcendência de Deus. Karl Barth chegou a ser conhecido como o teólogo do 'totalmente Outro'. Sua teologia não busca uma atitude conciliadora, como era o caso da teologia liberal, mas, antes, se constitui como uma teologia da crise, sem possibilitar nenhuma conciliação entre Deus e o Mundo, Deus e o homem. Esse modo de pensar traz questões sérias para a teologia: como conceber a realidade da revelação cristã? Como se concebe a unidade entre a realidade divina e a realidade humana? Como fazer agora após a substituição da tradicional compreensão metafísica da realidade pela compreensão histórica? Como o anuncio cristão pode se apresentar historicamente e ser ao mesmo tempo imperativo e certo?

\footnotetext{
${ }^{5}$ Rudolf Bultmann ${ }^{5}$ nasceu em 20 de Agosto de 1884 em Wefelstede (Oldenburg), sendo filho de pastor protestante. Foi colega de Karl Jaspers nos estudos secundários. Fez os estudos superiores em Tubingen, Berlin e Marburgo, laureando-se em 1910, sob a orientação de Johannes Weiss. Em 1916 foi professor extraordinário em Breslau, indo em 1920 para Giessen e Marburgo em 1921. Sua tese defendida em 1910 tinha por título $O$ estilo da pregação paulina e a diatribe cínico-estoica.

${ }^{6} \mathrm{O}$ termo "teologia liberal" foi utilizado pela primeira vez pelo teólogo de Halle, Johann Salomo Semler (1725-1791). Esta tendência teológica nasce do encontro do liberalismo com a teologia protestante. As suas características são: 1) assunção vigorosa do método históricocrítico e de seus resultados; 2) relativização da tradição dogmática da igreja particularmente da cristologia; 3) leitura predominantemente ética do cristianismo (...) visava harmonizar a religião cristã com a consciência cultural da época (cf Rosino Gibellini p. 19).

${ }^{7}$ Cf. CAVALIERI, Edebrande. A Teologia existencialista de Bultmann como expressão do pensamento moderno. In Teologia e Modernidade, p. 101-136.
} 
Todas essas questões não se apresentavam somente à pesquisa científica, elas tocaram violentamente toda a realidade da primeira metade do século XX. Se o século XIX representou o mais alto grau de otimismo (que ficou notório na teologia liberal), o seguinte foi açoitado por inúmeras crises, conflitos bélicos, governos totalitários, em suma, uma radical descrença nos poderes constituídos, e uma patente falência nas formas metafísicas de dizer a realidade.

\subsection{Bultmann e o existencialismo}

O existencialismo é, em grande parte, fruto desse desespero humano, ou melhor, este cenário produziu o ambiente que proporcionou uma reflexão filosófica que levasse em conta esse contexto. O pessimismo irá desembocar na convocação de uma subjetividade histórica capaz de construir e realizar novos projetos de humanidade ${ }^{8}$.

Ao falar do existencialismo Sartre afirma: "é uma doutrina que torna a vida humana possível e que, por outro lado, declara que toda a verdade e toda a ação implicam um meio e uma subjetividade humana" ". Antes do advento do existencialismo, o modo de pensar tradicional afirmava que no homem assim como na natureza em geral a essência sempre se define antes da existência. Somente Deus possui a antecedência da existência. Sartre dirá que "se Deus não existe, há pelo menos um ser no qual a existência precede a essência, um ser que existe antes de poder ser definido por qualquer conceito e que esse ser é o homem ou como diz Heidegger, a realidade humana" ${ }^{\prime 10}$.

Bultmann retoma esse princípio e afirma: tens que existir! Sem essa decisão ninguém pode entender uma só palavra da Bíblia que interpela a existência pessoal. Por isso, "escutar a palavra da Bíblia é algo que só pode ocorrer na decisão pessoal" 1 .

Nessa altura se faz necessário introduzir um outro tema da teologia de Bultmann (sem dúvida o mais importante de todos): a demitização. Sendo a palavra o sacramento por primazia, carece em todo o tempo ser interpretada. A interpretação, porém, não é qualquer interpretação, antes uma de caráter antropológico. Com isso Bultmann está assumindo radicalmente o homem entendido na mediação existencialista - como sujeito a quem se dirige a revelação.

\footnotetext{
${ }^{8}$ Cf. Ibidem. p. 105.

${ }^{9}$ SARTRE, Jean-Paul. O existencialismo é um humanismo. In Coleção Os pensadores. p. 4.

${ }^{10}$ Ibidem. p. 6.

${ }^{11}$ BULTMANN, Rudulf. Jesus Cristo e a Mitologia. In Demitologização. p. 77.
} 
Uma questão básica, portanto, é se essa revelação faz sentido ao homem da modernidade. Porque, se não faz sentido, também não o interpela, $\mathrm{e}$ se não interpela não é lugar de encontro com o revelado. Para que a palavra seja querigma ela precisa ser interpretada para o horizonte de cada tempo. Fazer isso para um tempo moderno consiste, portanto, demitizá-la. Essa questão é crucial para Bultmann:

Tudo isso é linguagem mitológica. Os elementos individuais podem ser facilmente descobertos na mitologia contemporânea da apocalíptica judaica e no mito gnóstico da redenção. Em se tratando de linguagem mitológica, ela é inverossimil para o ser humano de hoje, pois para este a concepção mítica do universo é algo passado. Portanto, a proclamação cristã de hoje se encontra diante da pergunta se ela espera do ser humano a aceitação da concepção mítica do universo passado, quando o conclama à fé. Se essa condição é algo impossivel, então lhe surge a pergunta se a proclamação do Novo Testamento possui uma verdade independente da concepção mítica do universo. Seria então a tarefa da teologia demitizar a proclamação cristãa $\tilde{a}^{12}$

\section{A questão da demitização como hermenêutica atualizadora do que- rigma}

$\mathrm{Na}$ verdade é preciso entender que a concepção do universo do Novo Testamento é mítica, como diz Bultmann. E, "Se quisermos, portanto, manter a validade da proclamação do Novo Testamento, então só nos resta um único caminho: o de sua demitização" ${ }^{13}$.

Como observa Rosino Gibellini, a tarefa da demitização é dupla: de um lado está sua via negativa, "de crítica da imagem do mundo como expressa no mito, e, consequentemente, da imagem mítica do mundo tal como expressa na Bíblia"14. Do outro lado se encontra a via positiva, "de esclarecimento da verdadeira intenção do mito e da verdadeira intenção das Escrituras bíblicas" ${ }^{\prime 15}$.

\subsection{O mundo mítico do Novo Testamento}

Demitizar não significa escolher partes do Novo Testamento que deveriam ser cortadas em função da sua incompreensão para o homem moderno.

\footnotetext{
${ }^{12}$ BULTMANN, Rudolf. Novo Testamento e a Mitologia. In Demitologização. p. 7.

${ }^{13}$ Ibidem. p. 13

${ }^{14}$ GIBELLINI, Rosino. Op cit. p.35.

${ }^{15}$ Ibidem.
} 
Demitizar é, antes, uma tarefa que toma todo o Novo Testamento, já que a imagem mítica do mundo apresentada nele é um a priori que enquadra todo o conteúdo e envolve toda a mensagem ${ }^{16}$.

A concepção do universo do Novo Testamento é mítica. $O$ universo é considerado como dividido em três andares. No meio se encontra a terra, sobre ela o céu, abaixo dela o mundo inferior. O céu é a moradia de Deus e das figuras celestiais, os anjos; o mundo inferior é o inferno, lugar de tormento. Mas também a terra não é só lugar do acontecer natural e cotidiano, da previdência e do trabalho, que conta com ordem e lei; é também cenário de poderes sobrenaturais, de Deus e de seus anjos, de Satã e de seus demônios. Os poderes sobrenaturais interferem nos acontecimentos naturais e no pensar, querer e agir do ser humano $^{17}$.

Como vemos, o que preocupa Bultmann não é o que faz da ação de Deus algo objetivo, mas que a mensagem do Novo Testamento, envolta deste modo numa compreensão pré-científica do mundo, permanece oculta para o homem moderno. Bultmann expressa essa sua percepção de forma bastante aguda quando afirma:

Não se pode utilizar luz elétrica e aparelho de rádio, em casos de doença empregar modernos meios médicos e clínicos, e simultaneamente acreditar no mundo dos espiritos e dos milagres do Novo Testamento. E quem supor que o pode para sua pessoa, deverá se dar conta de que se declará-lo como a postura da fé cristã, estará com isso tornando incompreensivel e impossivel a proclamação cristã no presente ${ }^{18}$.

\subsection{A verdadeira intenção do mito e das Escrituras Sagradas}

A eliminação dos elementos mitológicos não é simplesmente um requisito da erudição, ou uma empresa negativa. Tem também seu aspecto positivo em sua exigência de que a fé se encarne no homem de hoje como se encarnou nos homens de todas as épocas.

$O$ verdadeiro sentido do mito não é proporcionar uma concepção objetiva do universo. Ao contrário, nele se expressa como o ser humano se compreende em seu

\footnotetext{
${ }^{16}$ Bultmann dedica uma seção de seu Novo Testamento e a mitologia para tratar da tarefa da demitização, e, diz que está não consiste nem em seleção nem em cortes, mas, antes, numa total re-interpretação da mensagem do Novo Testamento para a humanidade de hoje.

${ }^{17}$ BULTMANN, Rudolf. Op cit. p. 5.

${ }^{18}$ BULTMANN, Rudolf. Op cit. p. 9.
} 
mundo. O mito não pretende ser interpretado cosmologicamente, mas antropologicamente - melhor: de modo existencialista ${ }^{19}$.

Bultmann pensa que a filosofia existencialista provê o instrumento necessário para re-interpretar a mitologia do Novo Testamento, sem, com isso, despojar o querigma de seu caráter essencial. $\mathrm{O}$ existencialismo não busca 'verdades eternas', mas busca a verdade de acordo com sua encarnação no concreto, no histórico, na existência. Isso o faz particularmente adaptado às necessidades da demitização do Novo Testamento ${ }^{20}$.

Que é, então, que deve se fazer com o a priori mítico neotestamentário? Considerá-los de modo existencial, a saber, procurar descobrir o sentido existencial que o texto pode oferecer. Demitizar, portanto, não significa negar os mitos, mas, interpretá-los existencialmente na perspectiva do homem moderno. Dessa tarefa depende o querigma cristão.

Em suma, a intuição de Bultmann quanto à demitização é bastante simples: a mensagem cristã, que se encontra comunicada numa linguagem própria de determinada cosmologia, precisa ser comunicada a outras realidades. Porém, nesse momento o próprio mito (como linguagem possível de um tempo) é confundido com a mensagem.

Portanto, a razão para a crítica do mito encontra-se no próprio mito, isto é, em suas concepções objetivantes, na medida em que sua verdadeira intenção de falar de um poder transcendente ao qual o mundo e o ser humano estão sujeitos é inibida e encoberta pelo caráter objativante de suas afirmações.

Por isso, também a mitologia do Novo Testamento não deve ser inquirida quanto ao seu conteúdo conceptual objetivante, mas quanto à compreensão da existência que se expressa nessas concepções. O que está em jogo é a verdade dessa compreensão, e sua verdade é afirmada pela fé, que não deve ser comprometida a aceitar o universo conceptual do Novo Testamento ${ }^{21}$.

Todo esse instrumental hermenêutico é efetivamente utilizado numa dupla intenção: na perspectiva do biblista, que quer saber o que diz realmente o Novo Testamento; e na perspectiva do teólogo, que se pergunta o que tem a dizer o Novo Testamento para o homem de hoje.

\footnotetext{
${ }^{19}$ Ibidem. p. 14.

${ }^{20}$ Cf. MACKINTOSH, H.R. Op cit. p.368-370.

${ }^{21}$ BULTMANN, Rudolf. Op cit. p.15.
} 


\section{Ressurreição na perspectiva bultmaniana: a centralidade da fé pascal}

"O ressurreto vem ao encontro na palavra pregada, e só nela. "Assim, a fé vem pela pregação, e a pregação pela palavra de Cristo" $(\mathrm{Rm} 10.17)^{22 \%}$. O Cristo ressurreto nos vem pela palavra da pregação e convoca-nos à fé. Não há meio pelo qual a história possa dar provas da ocorrência da ressurreição. "Podemos somente encontrar o Cristo ressurreto na pregação que a Igreja faz neste mundo" 23 .

Aqui se encontra o ponto mais alto de nossa reflexão: a demitização quer revelar o querigma, que encerra a mensagem cristã desde seu núcleo: a ressurreição como evento escatológico. Na ressurreição de Cristo, também nós somos ressuscitados, porém, essa novidade de vida não pode ser acessada como evento histórico-fatual, mas, como evento histórico, somente à medida que se torna lugar para a história de salvação da humanidade que faz a experiência do Cristo ressurreto em perspectiva existencial.

A proclamação da cruz como evento salvífico desafia o ouvinte a se apropriar de tal significado, deixando-se crucificar com Cristo (...) A ressurreição de Cristo, porém, não é ela um evento mítico por excelência? Em todo o caso, ela não é um evento histórico-fatual que devêssemos entender em sua significação. Pode o falar da ressurreição de Cristo ser outra coisa do que a expressão da significação da cruz? Expressaria alguma outra coisa do que isto, que a morte de Jesus na cruz não deve ser encarada como um morrer humano, mas como o juízo libertador de Deus sobre o mundo, o juízo de Deus que como tal tira o poder da morte? Não se expressa precisamente essa verdade na afirmação de que o crucificado não permaneceu na morte, mas ressurgiu? ${ }^{24}$.

\subsection{A centralidade do evento pascal para a fé cristã}

Bultmann assume o evento pascal (cruz e ressurreição) como elemento central da fé cristã, sem o qual esta não passaria dos primeiros momentos de sua existência. "De fato: cruz e ressurreição constituem como acontecimento 'cósmico' uma unidade, como é expressado, por exemplo, na seguinte frase: 'o qual foi entregue por causa das nossas transgressões, e ressuscitou por causa da nossa justificação' $(\mathrm{Rm} 4.25)^{25}$ ".

\footnotetext{
${ }^{22}$ Ibidem. p. 46.

${ }^{23}$ HORDERN, William. Teologia Contemporânea. p. 249.

${ }^{24}$ BULTMANN, Rudolf. Op cit. p. 41-42.

${ }^{25}$ Ibidem. p. 42.
} 
É verdade, que se poderia fazer uma crítica a Bultmann, no sentido de questioná-lo pela verificação histórico-fatual desse evento fundamental da fé cristã. Ou ainda perguntar de onde teria surgido essa fé relacionada com a ressurreição de Jesus dentre os mortos, e até mesmo sobre as passagens acerca do túmulo vazio. Bultmann não se cansa de responder, diante de tais questões, que, dessa forma, o que se estaria desejando é obter segurança a partir do mundo objetivo.

Tudo que as pesquisas não podem provar é que os Discipulos se tornaram crentes na ocorrência da ressurreição de Jesus de entre os mortos e saíram pelo mundo pregando que ela tinha acontecido. Isso jamais persuadirá o cético à fé. Ele pode tentar explicar tudo psicologicamente. Mas, enquanto isso acontece, o indivíduo que insiste na possibilidade de provar historicamente a ressurreição estará revelando desconhecimento do elemento que realmente interessa. A fé relacionada coma ocorrência da ressurreição de Jesus significa a mesma coisa para nós que significou para os primeiros Discipulos ${ }^{26}$.

Esse deslocamento que Bultmann faz do lugar teológico da ressurreição (da história para a Graça de Deus, que se revelando no Cristo ressurreto funda a possibilidade da existência autêntica), a coloca no centro mesmo de todo o seu sistema teológico. É no evento pascal que o querigma se encontra em seu momento pleno. E, é sobre essa plenitude querigmática que a interpretação/demitização deve se dar, revelando dessa forma, uma possibilidade renovada ao homem de hoje de fazer a experiência da existência autêntica. A páscoa de Cristo é revelação da graça de Deus.

Esta claro que o evento salvífico da morte e ressurreição de Cristo é o ato da graça proveniente de Deus, e que as diferentes locuções, nas quais é descrito esse ato, têm por finalidade expressar o inaudito desse acontecimento e seu poder que transforma radicalmente a situação humana. $\dot{E}$ um evento realizado exclusivamente a partir de Deus, para o ser humano nada mais do que dádiva, por meio de cuja recepção ele é libertado do perverso designio de ganhar sua vida, seu eu - no que ele justamente a perde -, para recebê-la como presente na justiça de Deus ${ }^{27}$.

Esse que é o ato supremo da graça de Deus, não pode ser apreendido em nenhuma outra instância menos profunda que a existência humana, por meio da experiência com a palavra anunciada. Não serão as provas históricas, arqueológicas ou jurídicas que revelarão ao homem a vida autêntica, mas

\footnotetext{
${ }^{26}$ HORDERN, William. Op cit. p. 250.

${ }^{27}$ BULTMANN, Rudolf. Teologia do Novo Testamento. p. 361.
} 
somente a experiência que atravessa a existência rompendo dessa forma todas as camadas de exterioridade.

A cruz e a ressurreição de Jesus são para a fé cristã, portanto, o evento escatológico no qual se pode passar da morte à vida. Porém, é necessário ainda explicitar, embora já tenhamos antecipado alguns elementos, como que se pode fazer essa passagem, qual o lugar teológico onde pede ser realizada. É o próprio Bultmann quem identifica esse lugar, dando a ele toda a importância:
Assim, somos remetidos de volta a essa questão: como se pode depreender da cruz ser ela a cruz de Cristo, o even- to escatológico? Como chegamos a crer na cruz como e- vento salvífico?
Aqui me parece haver apenas uma resposta: por ser as- sim proclamada, porque é proclamada como a ressurrei- ção. Cristo, o crucificado e ressurreto, se nos confronta na palavra da proclamação, em nenhum outro lugar. Jus- tamente a fé nessa palavra é em verdade a fé pascoal ${ }^{28}$.

\subsection{O querigma como lugar teológico da ressurreição}

No que tange a esse específico lugar teológico da ressurreição, bem como ao acesso exclusivo a ele via interpretação antropológico-existencial, e, de todo o seu poder de autenticidade existencial, Bultmann é bastante claro e incisivo:

Entraríamos num beco sem saída se nesse ponto quiséssemos retroceder, perguntando pela origem históricofatual da proclamação, como se esta pudesse evidenciar sua legitimidade. Isso significaria: querer fundamentar a fé na palavra de Deus mediante pesquisa historiográfica. A palavra da proclamação se nos confronta como palavra de Deus, diante da qual não podemos fazer perguntas de legitimação, mas que apenas pergunta a nós se queremos crer nela ou não (...) Fé e descrença não são, por isso, resolução cega e arbitrária, mas um sim ou um não compreensivo ${ }^{29}$.

Esse evento que toca as dimensões mais profundas da existência humana, o faz exatamente porque se encontra numa dimensão última dessa existência. "Localizando" esse ponto central da fé cristã para além das objetivações racionalistas do iluminismo e de seu correlato teológico, teologia liberal, Bultmann pretende ao mesmo tempo dar conta das inquietações bí-

\footnotetext{
${ }^{28}$ Ibidem. p. 44.

${ }^{29}$ Ibidem.
} 
blicas e teológicas. Assumindo a dimensão mitológica do Novo Testamento, a fim de interpretá-lo em dimensão antropológico existencial, ele pôde tanto afirmar a mensagem essencial do evento pascal, como mostrar sua atualidade para a humanidade cética da modernidade.

Bultmann reclama à fé a condição de ponto de partida para a existência cristã. Coisa que vinha sendo alienada ao cientificismo histórico-crítico da teologia liberal. É a palavra proclamada quem pode apresentar o mistério da fé, e, é esta fé quem conduzir a humanidade a uma existência autêntica. A aceitação da ressurreição daquele que com a morte derrotou o pecado, confere, como evento escatológico, a vida ressurreta aos que crêem. Como argumenta o próprio Bultmann:

A verdade da ressurreição de Cristo não pode ser compreendida antes da fé que reconhece o ressurreto como Senhor (...) Mas ela pode ser crida - e somente desta maneira - na medida em que ela ou o ressurreto está presente na palavra anunciada (...) Pois Cristo não está presente no querigma como uma grande personalidade histórica está presente em sua obra e em sua atuação histórica. Pois não se trata de um efeito que acontece na história, $e$ sim do fato de que uma pessoa histórica e seu destino estão alçados ao nível de acontecimento escatológico ${ }^{30}$.

Não estivesse bastante claro a centralidade do evento pascal no querigma cristão, e na fé que dele (e só dele) decorre, evocamos finalmente uma última fala de Bultmann com a qual abre sua monumental Teologia do Novo Testamento:

Fé cristã, no entanto, existe só a partir do momento em que existe um querigma cristão, isto é, um querigma que proclama a Jesus Cristo como ato salvífico escatológico de Deus, ou seja, Jesus Cristo, o crucificado e ressurreto. Isso só viria a acontecer no querigma da comunidade primitiva, e não já na pregação do Jesus histórico, embora muitas vezes a comunidade tivesse introduzido, no relato sobre ela, elementos de seu próprio querigma ${ }^{31}$.

\section{Uma conclusão ou uma chave para ler a demitização bultmaniana}

Uma das questões mais difíceis para compreender o pensamento de Bultmann, sobretudo, no que tange ao seu grande empreendimento teológico que é a demitização, é, sem dúvida, sua concepção de mito. No intuito de

\footnotetext{
${ }^{30}$ BULTMANN, Rudolf. Teologia do Novo Testamento. p. 373.

${ }^{31}$ Ibidem. p. 40.
} 
lançar alguma luz sobre esse ponto que, por vezes, se mostra obscuro apontaremos três maneiras de lidar com a mitologia presente na Escritura cristã ${ }^{32}$.

A primeira é simplesmente aceitá-la literalmente e, em grande medida é isto que faz o fundamentalismo. Mas, como observou Bultmann, isso é obviamente impossível para o homem moderno tendo em vista o atual conceito científico da realidade.

A segunda maneira de tratar com a mitologia do Novo Testamento é aquela do liberalismo teológico: rejeitar os elementos míticos do Novo Testamento. A teologia liberal se esforçou para conservar a mensagem do neotestamentária, porém acabou por reduzi-la a um conjunto de preceitos éticos.

Uma terceira maneira de tratar a mitologia do Novo Testamento é a que Bultmann assumiu em sua tarefa de demitização: ao invés de aceitar a mitologia de modo literal ou de rejeitá-la, é preciso interpretá-la com o auxilio da filosofia existencial de Heiddeger. Faz-se necessário, nesse sentido, levar o mito a sério, assumi-lo como portador de uma mensagem que precisa ser extraída com seus conteúdos existenciais.

Com essa chave de leitura é mais fácil compreender como Bultmann encarou o Novo Testamento na grande tarefa de anunciar o querigma cristão aos homens e mulheres de seu tempo.

Alessandro Rodrigues Rocha

Doutorando em Teologia pela PUC-Rio Coordenador Acadêmico da FATERJ

\section{Bibliografia}

BORNKAMM, Günther. Jesus de Nazaré. São Paulo: Editora Teológica, 2005.

BULTMANN, Rudolf. Demitologização: coletânea de ensaios. São Leopoldo: Sinodal, 1999. gica, 2004. .Teologia do Novo Testamento. São Paulo: Editora Teoló-

ERICKSON, Millard J. Opções Contemporâneas na Escatologia. São Paulo: Vida Nova, 1982.

GADAMER, G. Maestri e compagni nel cammino del pensiero: um seguardo retrospectivo. Brescia: Queriniana, 1980.

GIBELLINI, Rosino. Teologia do Século XX. São Paulo: Edições Loyola, 1998.

${ }^{32}$ Cf ERICKSON, Millard J. Opções Contemporânea na Escatologia. p. 30-43. 
HIGUET, Etiene A. (org). Teologia e Modernidade. São Paulo: Ed. Novo Século, 2005.

HORDERN, William E. Teologia contemporânea. São Paulo: Hagnos, 2003.

MACKINTOSH, H.R. Teologia Moderna. São Paulo: Ed. Novo Século, 2002.

SARTRE, Jean-Paul. O existencialismo é um humanismo. São Paulo: Abril cultural, 1978. Coleção Os pensadores. 